Supporting Information

\title{
New Lewis-Basic $N$-Oxides as Chiral Organocatalysts In Asymmetric Allylation of Aldehydes
}

Andrei V. Malkov, ${ }^{*}$ Mark Bell, Monica Orsini, Daniele Pernazza, Antonio Massa, Pavel Herrmann, Premji Meghani, and Pavel Kočovský *

\section{Table of Contents}

General Methods $\quad$ S2

${ }^{1} \mathrm{H}$ NMR spectrum of $N$-monoxide $(+)-8 \quad \mathrm{~S} 3$

${ }^{13} \mathrm{C}$ NMR spectrum of $N$-monoxide $(+)-8 \quad \mathrm{~S} 4$

${ }^{1} \mathrm{H}$ NMR spectrum of $N$-monoxide (-)-9 S5

${ }^{13} \mathrm{C}$ NMR spectrum of $N$-monoxide (-)-9 $\quad$ S6

${ }^{1} \mathrm{H}$ NMR spectrum of $N$-monoxide (-)-10 $\quad \mathrm{S} 7$

${ }^{13} \mathrm{C}$ NMR spectrum of $N$-monoxide (-)-10 S8

${ }^{1} \mathrm{H}$ NMR spectrum of $N$-monoxide (-)-11 S9

${ }^{13} \mathrm{C}$ NMR spectrum of $N$-monoxide (-)-11 $\quad \mathrm{S} 10$ 
General Methods. Melting points were determined on a Kofler block and are uncorrected. Optical rotations were recorded in $\mathrm{CHCl}_{3}$ at $25^{\circ} \mathrm{C}$ unless otherwise indicated, with an error of $\leq \pm 0.1$. The $[\alpha]_{\mathrm{D}}$ values are given in $10^{-1} \mathrm{deg} \mathrm{cm}^{3} \mathrm{~g}^{-1}$. The NMR spectra were recorded in $\mathrm{CDCl}_{3},{ }^{1} \mathrm{H}$ at $400 \mathrm{MHz}$ and ${ }^{13} \mathrm{C}$ at $100.6 \mathrm{MHz}$ with chloroform- $d_{1}\left(\delta 7.26,{ }^{1} \mathrm{H} ; \delta\right.$ $77.0,{ }^{13} \mathrm{C}$ ) as internal standard unless otherwise indicated. Various 2D-techniques and DEPT experiments were used to establish the structures and to assign the signals. The IR spectra were recorded for $\mathrm{CHCl}_{3}$ solutions. The mass spectra (EI and/or $\mathrm{CI}$ ) were measured on a dual sector mass spectrometer using direct inlet and the lowest temperature enabling evaporation. All reactions were performed under an atmosphere of dry, oxygen-free nitrogen in oven-dried glassware, twice evacuated and filled with inert gas. Solvents and solutions were transferred by syringe-septum and cannula techniques. All solvents for the reactions were of reagent grade and were dried and distilled immediately before use (dichloromethane from calcium hydride). Petroleum ether refers to the fraction boiling in the range of $60-80{ }^{\circ} \mathrm{C}$. Yields are given for isolated products showing one spot on a TLC plate and no impurities detectable in the NMR spectrum. The identity of the products prepared by different methods was checked by comparison of their NMR, IR, and MS data and by the TLC behavior. The chiral GC and HPLC methods were calibrated with the corresponding racemic mixtures. $(+)$ - $\alpha$-Pinene $(+)-6$ was purchased from Aldrich; according to GC analysis on a Supelco $\beta$-DEX 120 column the ee was 90\%. (-)-Pinocarvone (-)-24 was obtained on a $40 \mathrm{~g}$ scale from $(+)-\alpha$-pinene $(+)-23$ via the photochemical oxidation (99\%) according to the Mihelich procedure. ${ }^{15}$ The Kröhnke salt 25 was prepared from $t$-butyl $\alpha$-bromoacetate and pyridine by refluxing in ethyl acetate in the same manner as the corresponding ethyl ester. ${ }^{8 c, 16}$ The trichlorosilyl enol ethers were prepared according to the literature procedures. ${ }^{28}$

(S)-(-)-1-Phenyl-hexa-1,5-dien-3-ol: $[\alpha]_{\mathrm{D}}-36.9\left(c\right.$ 1.06, $\left.\mathrm{CHCl}_{3}\right)$ and $+10.3(c$ 1.31, $\left.\mathrm{Et}_{2} \mathrm{O}\right) ;{ }^{1} \mathrm{H}-\mathrm{NMR} \delta 1.74(\mathrm{br} \mathrm{s}, 1 \mathrm{H}), 2.28-2.40(\mathrm{~m}, 2 \mathrm{H}), 4.27-4.32(\mathrm{~m}, 1 \mathrm{H}), 5.09-5.15(\mathrm{~m}, 2 \mathrm{H})$, 5.74-5.84 (m, $1 \mathrm{H}), 6.18$ (dd, $J=15.9,6.3 \mathrm{~Hz}, 1 \mathrm{H}), 6.55$ (d, $J=15.8 \mathrm{~Hz}, 1 \mathrm{H}), 7.15-7.33$ (m, 5 $\mathrm{H})$; chiral HPLC (Chiralcel OD-H, hexane/2-propanol 9:1, $0.75 \mathrm{~mL} / \mathrm{min})$ showed $83 \%$ ee $\left(t_{\mathrm{R}}=\right.$ $10.2 \mathrm{~min}, t_{\mathrm{S}}=14.9 \mathrm{~min}$.

1-Cyclohexyl-but-3-en-1-ol: ${ }^{1} \mathrm{H}-\mathrm{NMR} \delta$ 0.81-1.78 (series of m, $12 \mathrm{H}$ ), 2.04-2.08 (m, 1 H), 2.24-2.28 (m, $1 \mathrm{H}), 3.32-3.33(\mathrm{~m}, 1 \mathrm{H}), 5.05-5.09(\mathrm{~m}, 2 \mathrm{H}), 5.72-5.82(\mathrm{~m}, 1 \mathrm{H})$; chiral GC (Supelco $\beta$-DEX 120 column, oven $100{ }^{\circ} \mathrm{C}$, isothermic) showed $4 \%$ ee $\left(t_{\text {minor }}=38.7 \mathrm{~min}, t_{\text {major }}=\right.$ $39.2 \mathrm{~min})$. 


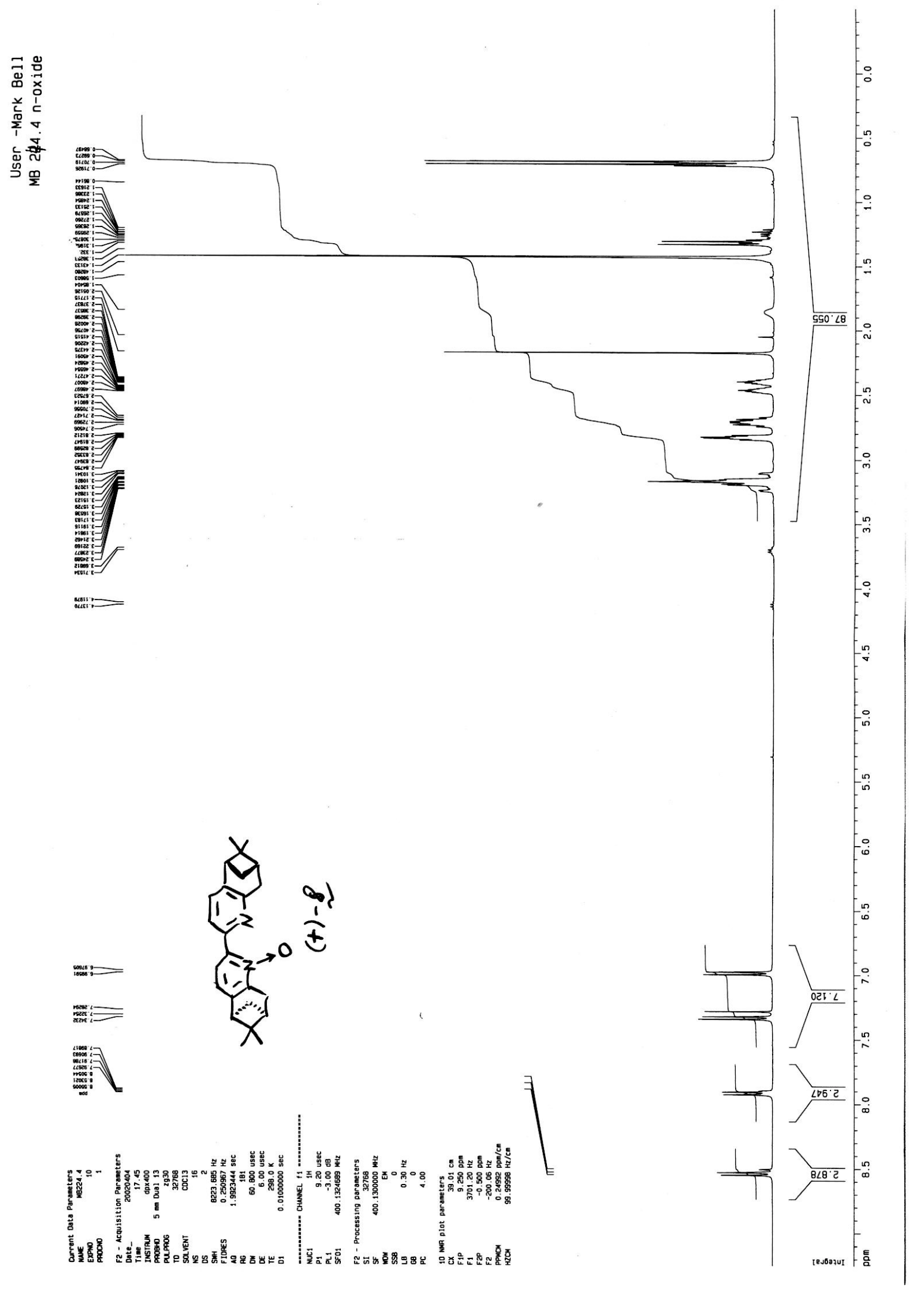




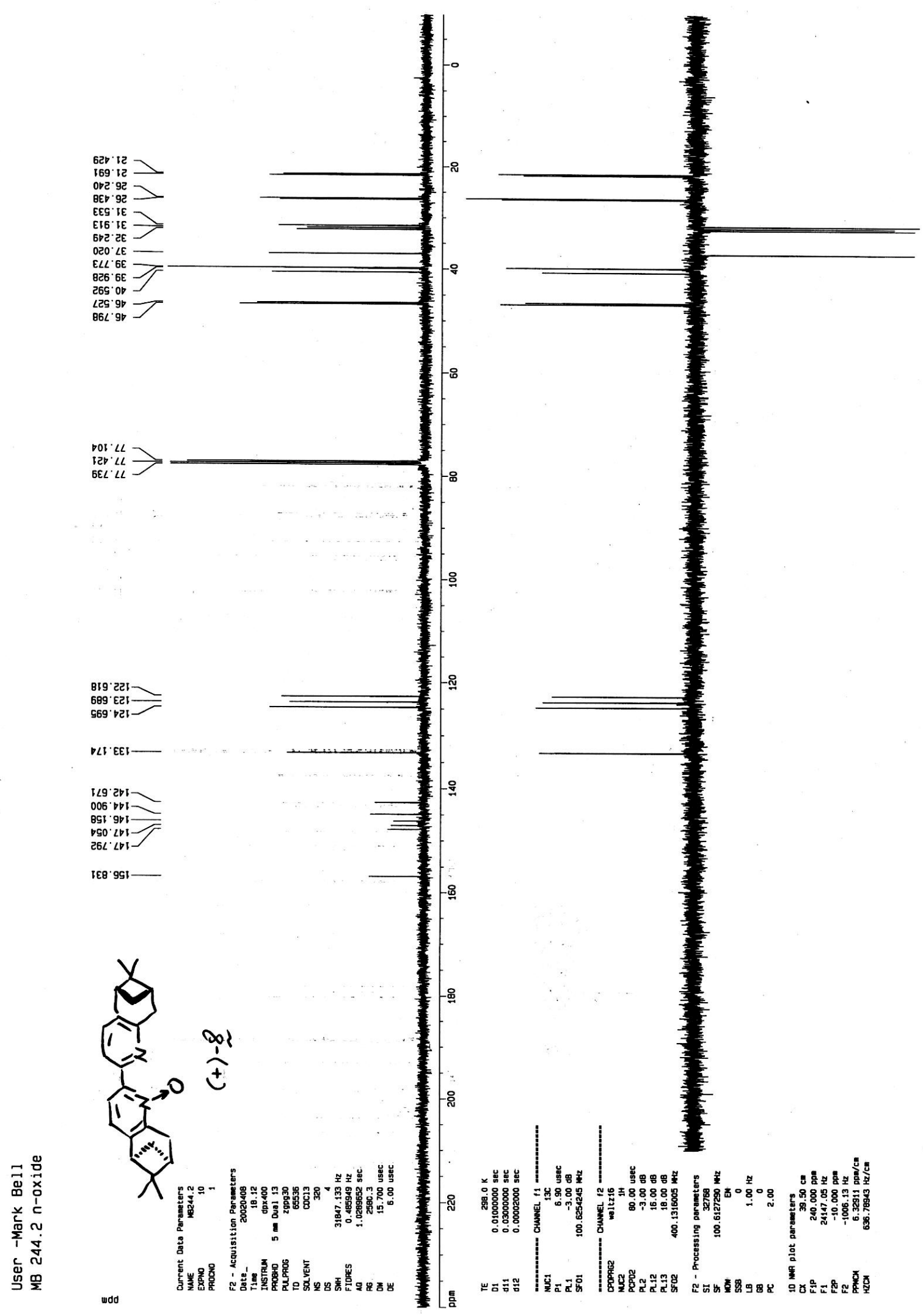




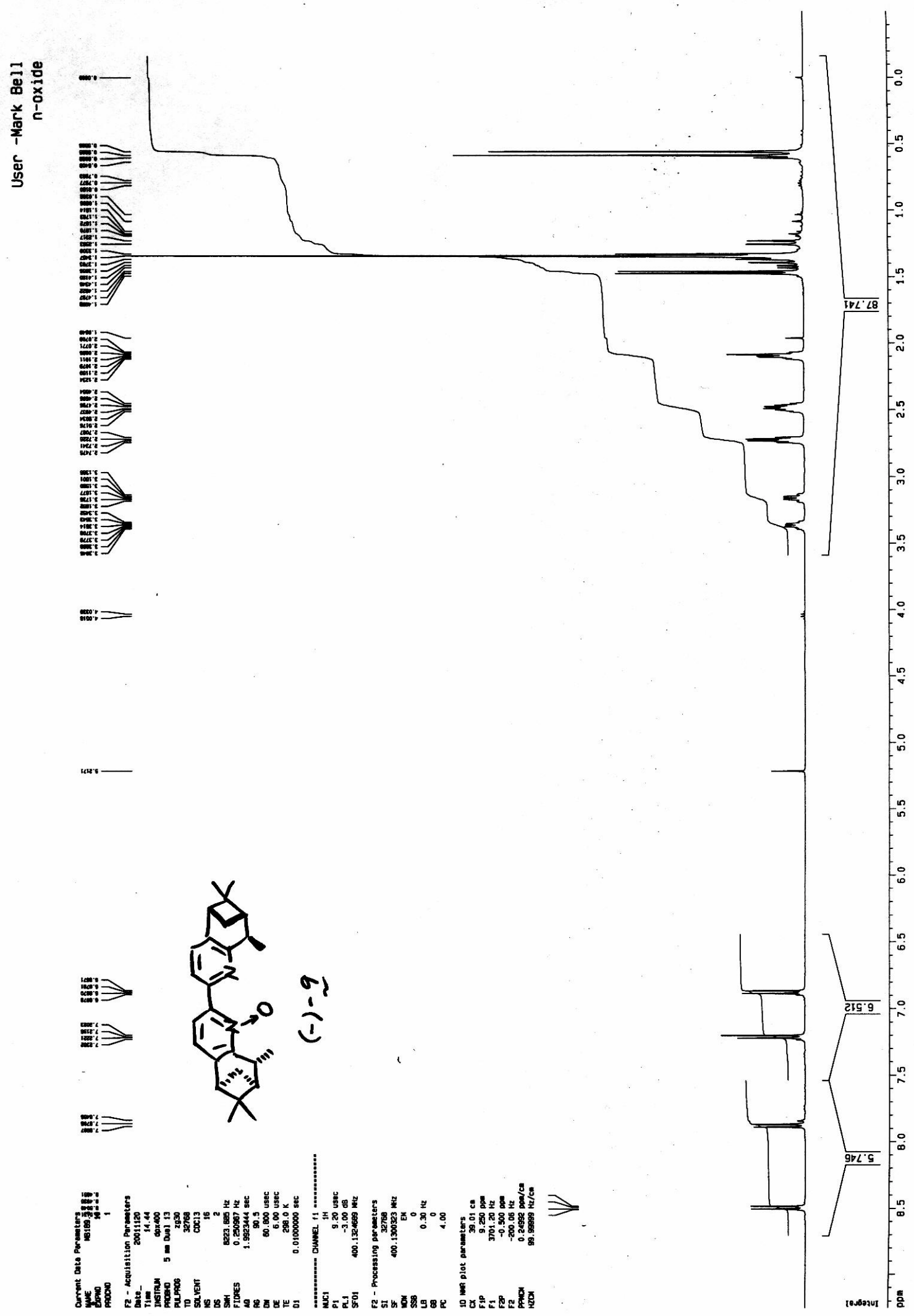




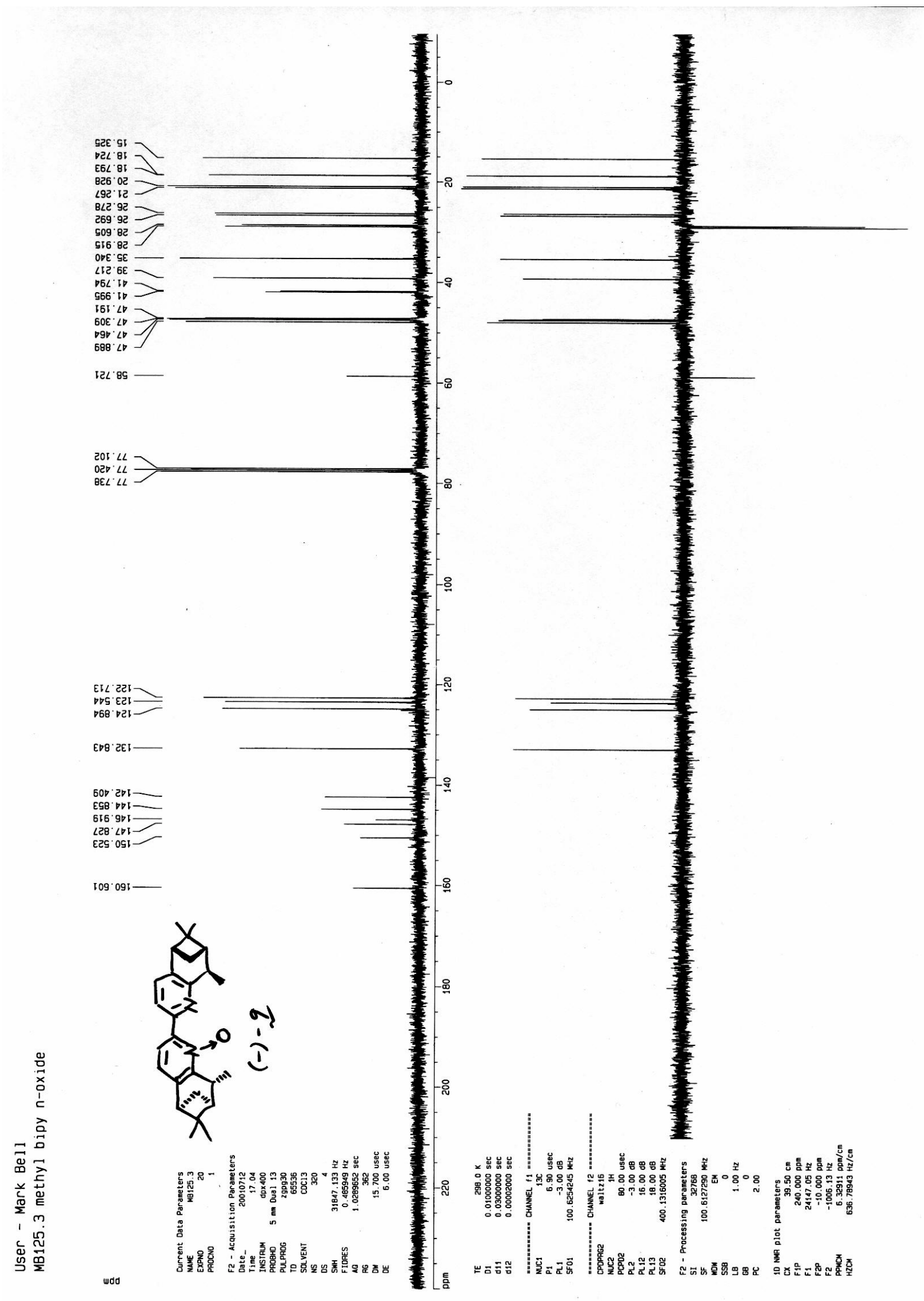




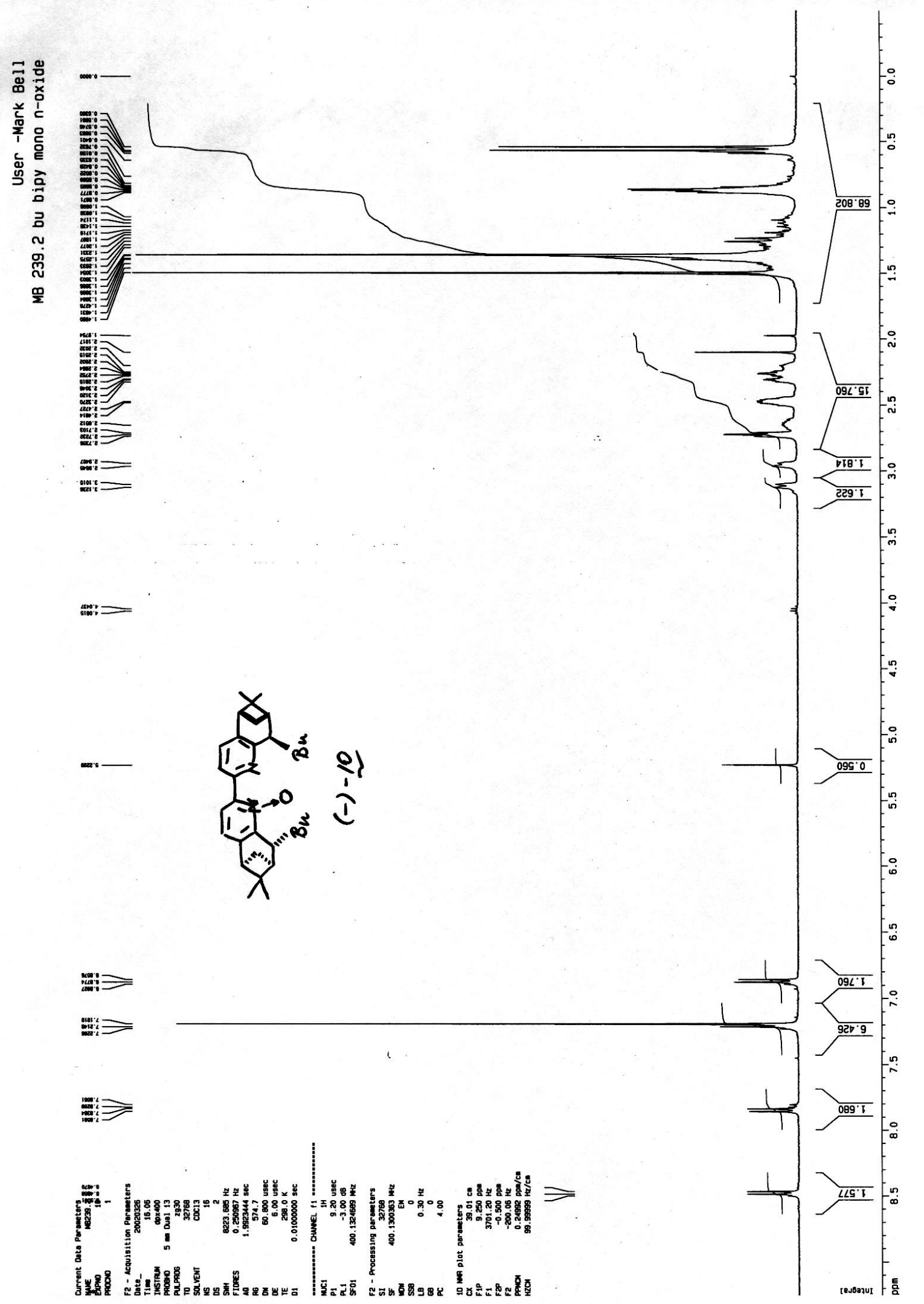




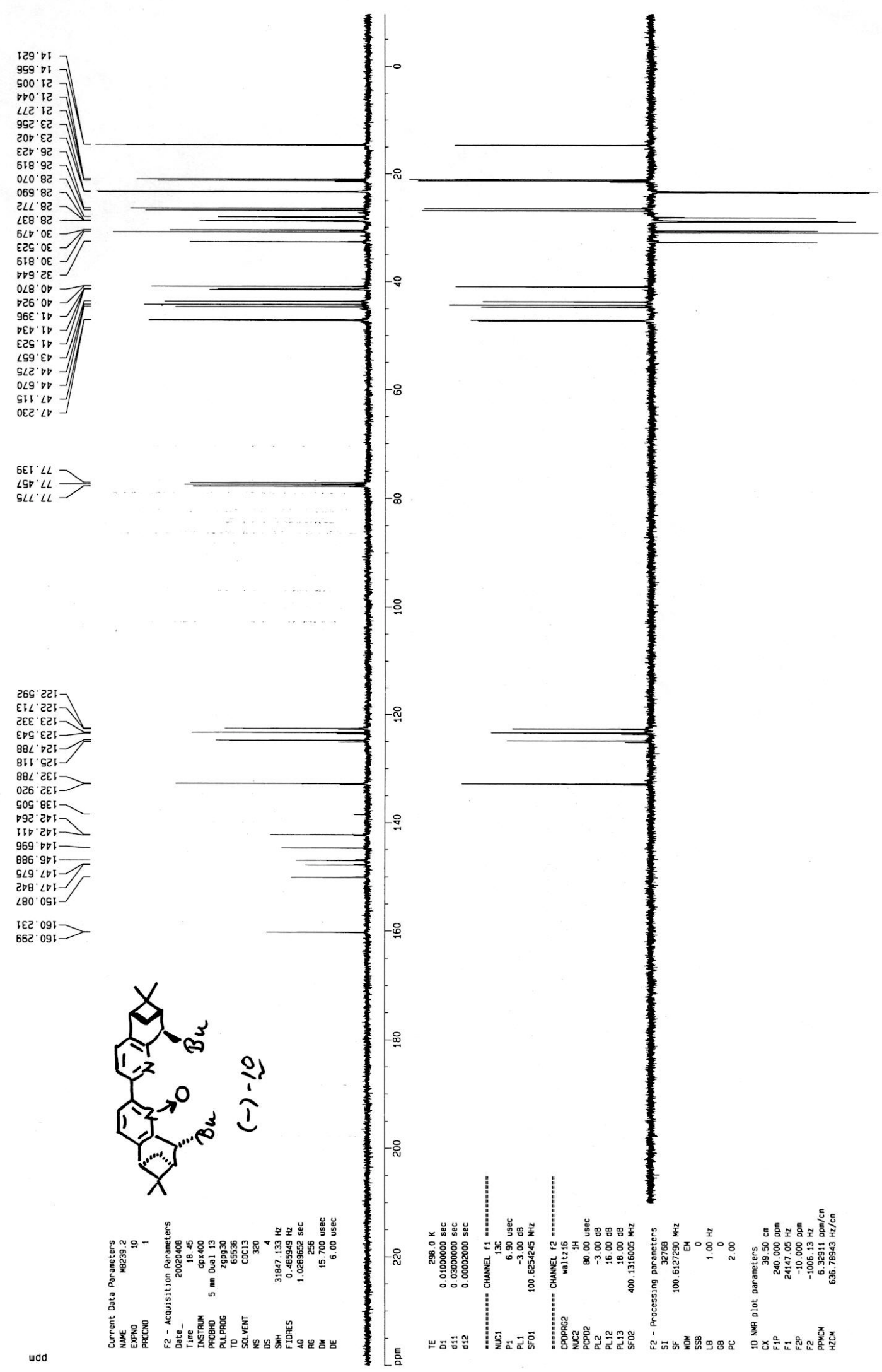




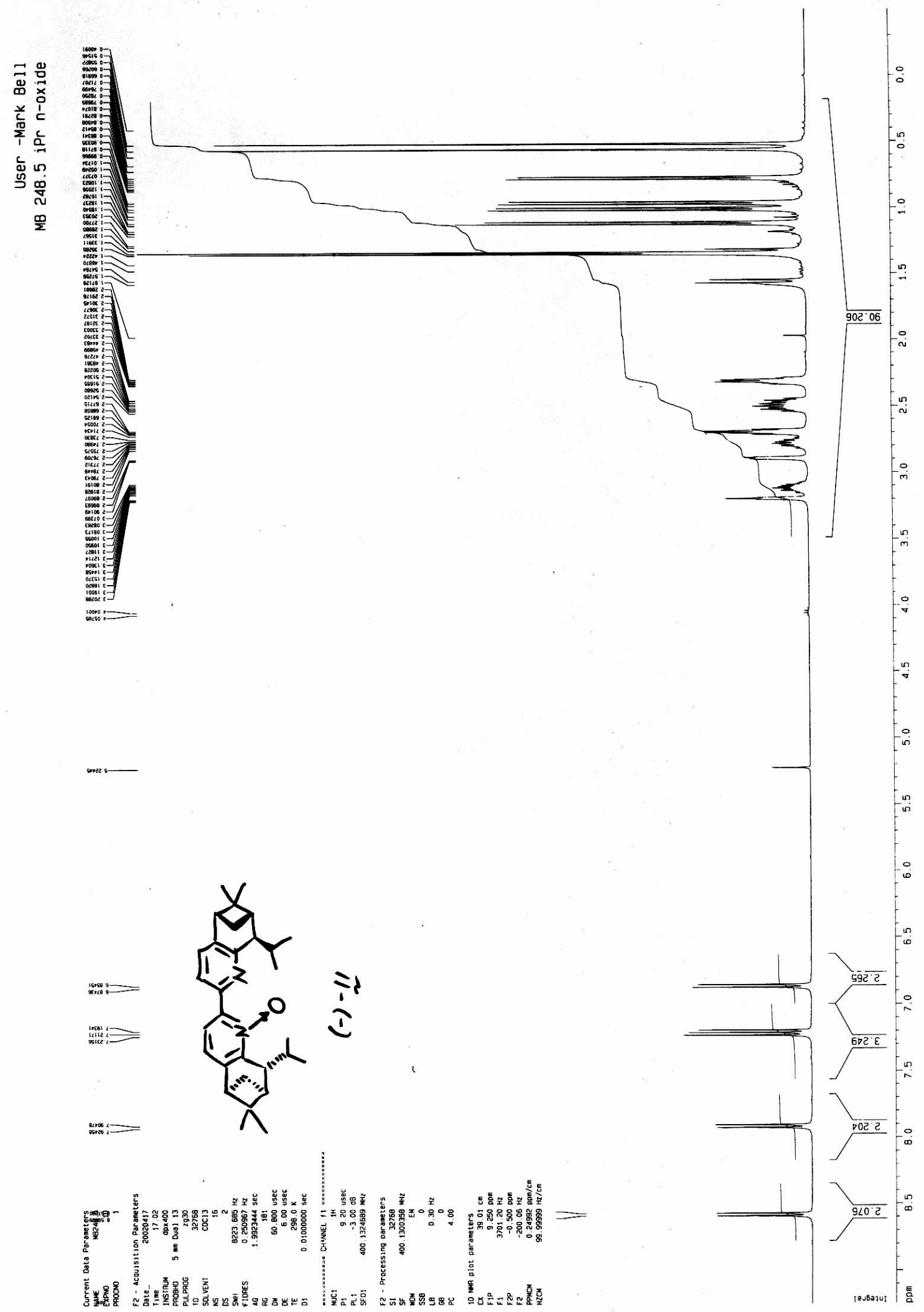




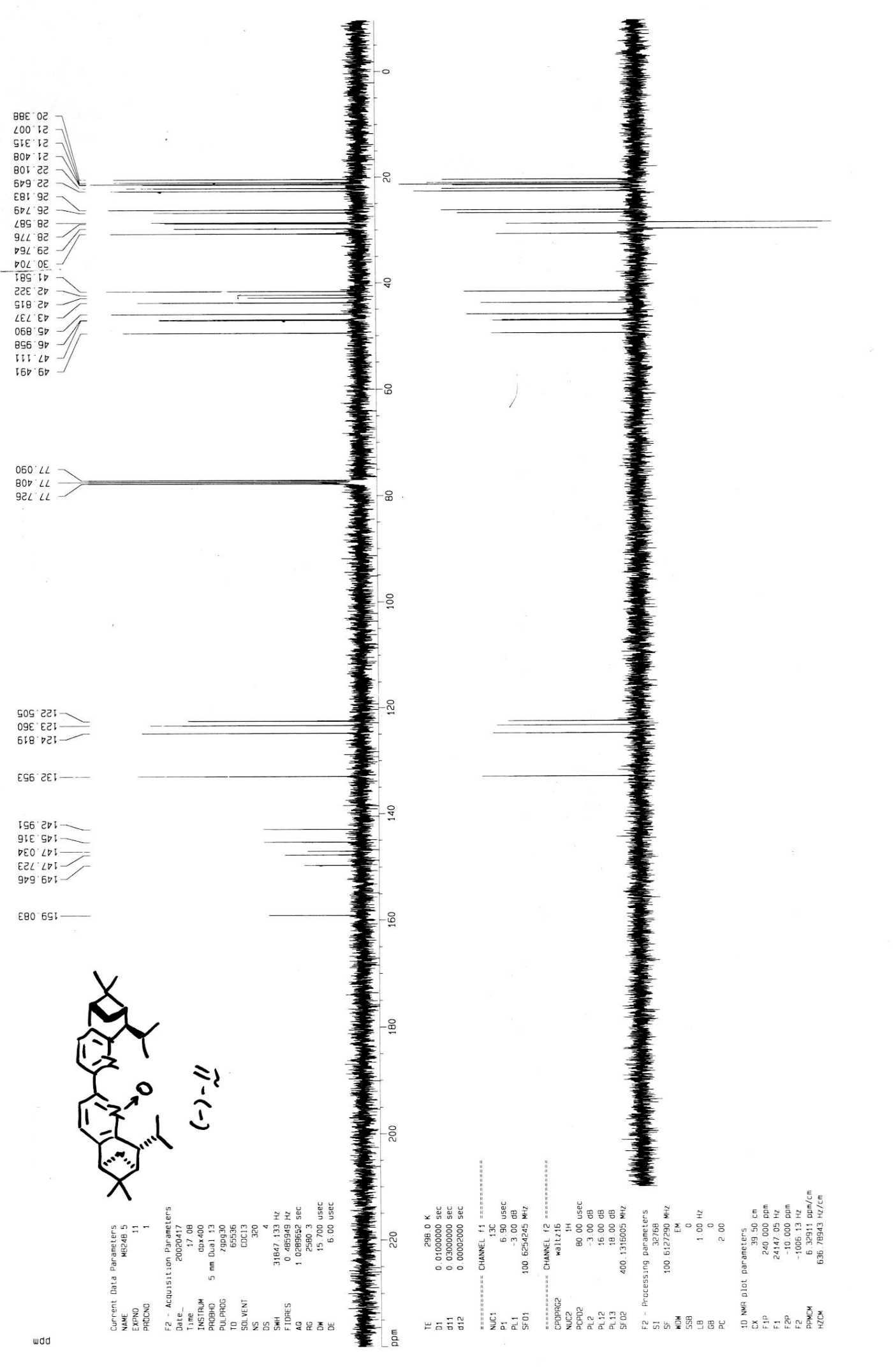

